\title{
Assessing climate change impacts, sea level rise and storm surge risk in port cities: a case study on Copenhagen
}

\author{
Stéphane Hallegatte • Nicola Ranger • Olivier Mestre • \\ Patrice Dumas · Jan Corfee-Morlot • \\ Celine Herweijer · Robert Muir Wood
}

Received: 28 July 2009 / Accepted: 6 July 2010 / Published online: 7 December 2010

(C) Springer Science+Business Media B.V. 2010

\begin{abstract}
This study illustrates a methodology to assess the economic impacts of climate change at a city scale and benefits of adaptation, taking the case of sea level rise and storm surge risk in the city of Copenhagen, capital of Denmark. The approach is a simplified catastrophe risk assessment, to calculate the direct costs of storm surges under scenarios of sea level rise, coupled to an economic input-output (IO) model. The output is a risk assessment of the direct and indirect economic impacts of storm surge under climate change, including, for example, production and job losses and reconstruction duration, and the benefits of investment in upgraded sea defences. The simplified catastrophe risk assessment entails a statistical analysis of storm surge characteristics, geographical-information analysis of population and asset exposure combined with aggregated vulnerability information. For the city of Copenhagen, it is found that in absence of adaptation, sea level rise would significantly increase flood risks. Results call for the introduction of adaptation in long-term urban planning, as one part of a comprehensive strategy to manage the
\end{abstract}

S. Hallegatte $(\bowtie) \cdot$ P. Dumas

Centre International de Recherche sur l'Environnement et le Développement, Paris, France e-mail: hallegatte@centre-cired.fr

S. Hallegatte $\cdot$ O. Mestre

Ecole Nationale de la Météorologie, Météo France, Toulouse, France

N. Ranger

London School of Economics and Political Science, London, UK

N. Ranger

Grantham Research Institute on Climate Change and the Environment, London, UK

J. Corfee-Morlot

Organisation for Economic Co operation and Development, Paris, France

C. Herweijer · R. M. Wood

Risk Management Solutions Limited, London, UK 
implications of climate change in the city. Mitigation policies can also aid adaptation by limiting the pace of future sea level rise.

\section{Introduction}

Estimating climate change economic impacts is a difficult task, because of the complexity of the interface between climate change, society and the world economy. This report illustrates a methodology to estimate economic impacts of climate change at city scale, taking the example of sea level rise and storm surge risks in a coastal city. Climate change impacts in coastal cities are expected to represent a major challenge this century, with millions of exposed people and thousands of billions of USD of exposed assets at the global scale (Hanson et al. 2011, in this volume).

The methodology applied in this report is presented in detail in Hallegatte et al. (2011, in this volume). It is based on a series of steps: (1) a statistical analysis of past storm surges in the studied city; (2) a geographical-information analysis of the population and asset exposure in the city, for various sea levels and storm surge characteristics; (3) an assessment of direct economic losses in case of storm surge (i.e. of the damages to buildings and building content), excluding human life losses and other intangible direct impacts; (4) an assessment of the corresponding indirect losses - in the form of production and job losses, reconstruction duration, amongst other loses-using an adaptive regional input-output model (ARIO, Hallegatte 2008); (5) a risk analysis of the effectiveness of coastal flood protections, including risk changes due to climate change and sea level rise.

This methodology is applied in Copenhagen (København), the capital of Denmark, and the centre of the Swedish-Danish Oresund (Øresund) region. As a lowlying city with a significant number of people and amount of property lying close to the water level, Copenhagen is potentially vulnerable to the effects of natural variability in sea level and, on decadal timescales, anthropogenic sea level rise. This study explores how storm surge risk might change in the future as a result of anthropogenic climate change and the implications for investment in protection infrastructure. In this analysis, all other impacts (e.g., flooding due to heavy precipitation) are disregarded, and the proposed methodology does not pretend to assess the total macroeconomic cost of climate change. The basic methodology presented here however could be extended to assess a range of different impacts areas or sectors.

Considering the large uncertainty on future sea level rise (e.g., IPCC 2007; Rahmstorf 2007; Pfeffer et al. 2008), this analysis is not based on a single sea level rise scenario. Instead, several possible amplitudes of sea level rise are considered, from 0 to $125 \mathrm{~cm}$, and results are presented in all these cases without trying to aggregate results for these various possible futures. This approach allows to account easily for any new information on future climate change, to assess the robustness of our results and their sensitivity to the amplitude of sea level rise, and to inform the reader on sea level rise consequences, regardless of his or her beliefs about future sea level rise.

The report begins with an overview of the geography of Copenhagen and estimates present and future storm surge activity. Section 3 presents an analysis of the exposure of population and assets (residential, commercial, and industrial) to sea levels. Section 4 then uses a simplified vulnerability function and an economic input-output model of the Capital Region of Denmark to investigate the potential 
direct and indirect losses for the city, including current protection. To demonstrate the broader applicability of the approach, Section 5 concludes and discusses more generic adaptation and mitigation options to limit flood risks.

\section{Context}

\subsection{Geography of Copenhagen}

Copenhagen (København) is located on the east side of the Danish island of Zealand, and partly upon the island of Amager (Fig. 1). The coastline of Copenhagen lies along the Danish Inner Waters and essentially upon the Baltic Sea. Copenhagen is a lowlying city, with the highest ground around $45 \mathrm{~m}$ above sea level. In terms of total insured value (TIV), most of the assets of Copenhagen are in the residential sector (more than 120 billions Euros), while industrial and commercial sectors represent, respectively, about 8 and 50 billion Euros. Agriculture is marginal in the region. In spite of its importance, data on infrastructure (especially transport infrastructure) was not available, and simple extrapolation methods had to be used (see Section 4.1).

\subsection{Current variability in sea levels in Copenhagen}

The low elevation of the city leaves its population and assets potentially exposed to variations in sea level. However, the city's position upon the Danish Inner Waters and Baltic Sea means that it experiences relatively small tidal changes in sea level. More significant changes in sea level are caused by the strong winds in the lowpressure storm systems that cross the Baltic region during winter. As storms pass over the sea, they can create storm surges; low atmospheric pressure and winds cause an increase in water levels at nearby coasts that can lead to flooding. Storm surges tend to occur more frequently and intensely along the North Sea coast (i.e. away from Copenhagen) than in the Danish Inner Waters. Copenhagen itself is also well protected by the surrounding topography and therefore, storm surge events are relatively rare. However, large surges are not unheard of; the city can be vulnerable when low pressure systems track northwards over the continent and into the Baltic.

Fig. 1 Schematic view of Copenhagen, Denmark

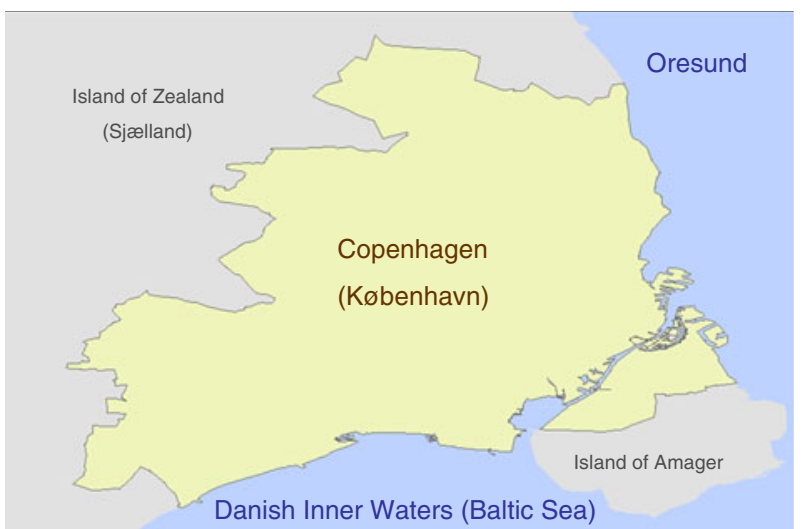


Fig. 2 Storm surge return water level $(\mathrm{cm})$ corresponding to various return-periods, up to 1,000 years. Note: the 117 years of data are reproduced with circles. The presented data was de-trended for extreme analysis

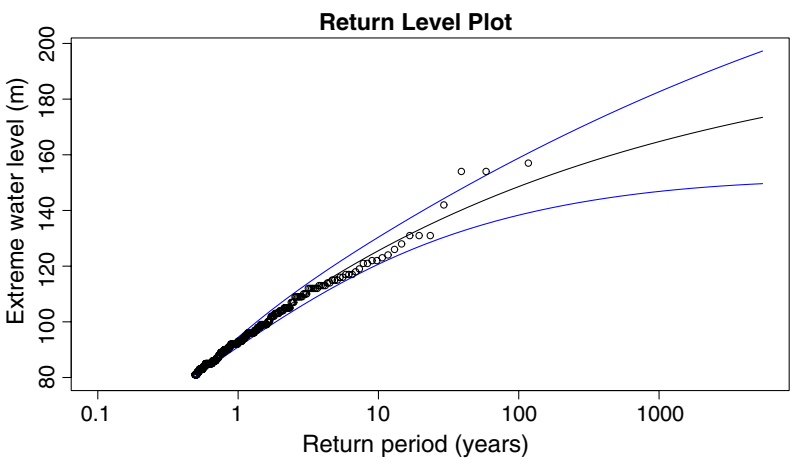

Historical storm surges have affected the Danish Inner Waters in the past. The largest events in the Copenhagen harbour record occurred in 1902 (154 cm above normal sea level) and $1921(157 \mathrm{~cm})$; no information about flooded areas or damages are available. The largest storm surges in recent history occurred during the winters of 2006 and 2007 (with recorded water levels of 131 and $142 \mathrm{~cm}$ ). These events did not lead to significant damages in Copenhagen.

Figure 2 shows the estimated storm surge water level corresponding to various return periods. Return periods are a measure of frequency; for instance, if the 100year flood is at $150 \mathrm{~cm}$ above normal sea level, it means that there is a $1 / 100=$ $1 \%$ chance of having a flood higher than $150 \mathrm{~cm}$ every year. This analysis uses local sea level data (1890 to 2007) provided by the Danish Coastal Authority ${ }^{1}$ (Kystdirektoratet) and produced by the Danish Meteorological Institute (DMI). The data set contains 256 events during which water level was at least $80 \mathrm{~cm}$ above the mean sea level. Relative frequencies of high-water events of various amplitudes are estimated using a Peak Over Threshold (POT) approach (See Coles 2001). The shape parameter of the Generalized Pareto Distribution (GPD) is found significantly lower than 0 with a $p$ value lower than $0.1 \%$ ( $\xi$ estimate: -0.155 with corresponding standard error 0.05). This implies that the underlying surge distribution is light tailed and upper bounded at $2.02 \mathrm{~m}$. According to the analysis presented here, the water level of the 20-, 50- and 100-year return-period events are, respectively, $135 \mathrm{~cm}$, $145 \mathrm{~cm}$ and $150 \mathrm{~cm}$ (Fig. 2) ${ }^{2}$. These are slightly lower than the average for the Danish Inner Waters. The distribution parameters estimated here are consistent with the statistical analysis performed at the Danish Coast Authority, but may be conservative as considerably larger surges predating measurements (e.g. in 1872) have been observed along parts of the Copenhagen coastline.

\footnotetext{
${ }^{1}$ We would like to thank Carlo Sørensen for his help in obtaining this data.

${ }^{2}$ According to these estimates, the water level corresponding to the m-year event is given by: $\mathrm{r}_{\mathrm{m}}=\mathrm{u}+\sigma / \xi \cdot\left((\mathrm{m} \cdot \text { nobs } \cdot \text { rate })^{\xi}-1\right)$,

where $\mathrm{u}$ is $80 \mathrm{~cm} ; \sigma$ is 18.91 ; nobs $=365$; rate $=5.53 \cdot 10^{-3}$ and $\xi=-0.154$. This function is plotted in
} Fig. 2 . 
The risk of coastal flooding in Denmark is relatively low at present. The areas worst affected by storm surges on the North Coast are not densely populated and are well protected. Further, the weather forecasting and warning systems established in Denmark have proven to be efficient to prevent human and economic losses from extreme events. Also, extreme storm surges in Copenhagen are limited and cannot exceed $2 \mathrm{~m}$ according to our statistical analysis, making it very easy to protect the city with sea walls and dikes.

\subsection{The effects of climate change on sea levels around Copenhagen}

Observed sea level change Global mean sea levels rose by around $17 \mathrm{~cm}$ over the twentieth-century, driven largely by the thermal expansion and melting glaciers, ice caps and ice sheets associated with anthropogenic global warming. On top of this global trend, there are significant regional differences in sea level change due to changes in ocean circulation and atmospheric pressure. Because of natural variability, it is more difficult to detect a climate-change signal in the local sea level in Copenhagen than in global sea level. Over the last century, a linear trend of $0.44 \mathrm{~mm}$ per year (i.e. $4 \mathrm{~cm}$ per century) can be observed in Copenhagen water level data from the city Coastal Authority. The difference between this observed local trend and the global rise in sea level is due to local factors (changes in ocean and atmospheric circulation and local uplift ${ }^{3}$ ) and possibly to measurement and trendextraction errors. The respective influence of these factors is still unclear.

Expected global sea level rise Global sea levels are projected to continue to rise as the world warms, increasing mean sea level rise at a local level. The 2007 Fourth Assessment Report of the Intergovernmental Panel on Climate Change (IPCC) projected that global mean sea levels would rise by 18-59 $\mathrm{cm}$ above 1990 levels by the 2090s (where the lower bound corresponds to the lower estimate for the lowest emissions scenario, and the higher bound corresponds to the upper estimate for the highest scenario). These projections, however, do not fully include contributions from the melting ice sheets (due to the limitations of the modelling techniques used). Other analyses (e.g., Rahmstorf 2007; Pfeffer et al. 2008) suggest global sea level rise between 50 and $200 \mathrm{~cm}$ above 1990 levels by 2100. Considering this uncertainty, our analysis is not based on a single sea level rise scenario, but on several possible amplitudes of sea level rise, from 0 to $125 \mathrm{~cm}$. Results are presented in all these possible cases and the consequences of this uncertainty are discussed in the conclusion.

Expected regional sea level rise In terms of regional changes, the IPCC found that sea level rise could be greater than the global average around northern Europe. Their Fourth Assessment Report projects a 18-59 cm rise in global mean sea level by the 2090s, but sea levels could rise by an additional $15-20 \mathrm{~cm}$ in the region due to changing climate patterns (air and water currents), reaching up to $38-79 \mathrm{~cm}$ around

\footnotetext{
${ }^{3}$ Geological uplift is the vertical elevation of the Earth's surface in response to natural causes (including the removal of Pleistocene ice sheets). The National Space Institute of the Technical University of Denmark estimates that the land uplift in Copenhagen is about $1.2 \mathrm{~mm}$ per year (information kindly provided by Per Knudsen).
} 
Denmark. However, these estimates are considered highly uncertain and will not be used in this study. Moreover, any local vertical land movements would need to be considered to estimate the overall mean sea level change. As Copenhagen is experiencing uplift, this will offset a portion of the increase in sea levels due to anthropogenic warming. In this analysis, however, these estimates will not be used and we will assume that sea level in Copenhagen will rise at the global level.

\subsection{Expected change in storm surges}

Climate change can affect water levels around Copenhagen in two ways; firstly, by simply raising the mean sea level and also by changing the variability in sea levels through, for example, changes in storminess, in particular, changes in the characteristics of extra-tropical cyclones. For example, an increase in the frequency of extra-tropical cyclones would reduce the return period of present-day storm surge events; whereas an increase in the intensity of events could increase the return period of weak events and reduce the return period of intense events. Both could potentially increase the risks associated with storm surges. It is not yet clear how climate change will influence the characteristics of extra-tropical cyclones. While evidence suggests that extra-tropical cyclones could become less frequent in both hemispheres, there could be a larger number of the most intense storms (e.g., Lambert and Fyfe 2006; Yin 2005; Lambert 2004; Leckebusch and Ulbrich 2004; Lozano 2004; Fyfe 2003; Geng and Sugi 2003; Lambert 1995). The most robust result is that there will be a poleward shift in the position of the storm tracks (e.g. Bengtsson et al. 2006; Salathé 2006; Fischer-Bruns et al. 2005; Yin 2005; Fyfe 2003; Geng and Sugi 2003; Kushner et al. 2001). In Europe, studies project an increase in storm track density (the number of storms) over Northwestern Europe, in particular, the UK and Scandinavia (Bengtsson et al. 2006; Lozano et al. 2004; Fischer-Bruns et al. 2005). There is also evidence that the intensity of storms will increase over Europe. ${ }^{4}$ Long-term records of sea levels around Europe also show signs of an increasing trend in the frequency of extreme sea levels (i.e. a reduced return-period for intense events) (Woodworth and Blackman 2002; Bouligand and Pirazzoli 1999). A number of modelling studies suggest that, in the future, increases in extreme wave height are likely to occur in the mid-latitude oceans (e.g. Wang et al. 2004; Caires et al. 2006). Woth et al. (2006) found that, for the North Sea, a 100-year event could become 10-20 cm higher than today by the 2080s. Lowe and Gregory (2005) find a 50-year return-period storm surge event becomes approximately 40-60 cm higher than today around the eastern coast of Denmark by the end of this century (for a medium-high emissions scenario). In the Baltic Sea, Meier (2006) found that water levels associated with a 100-year event increase more rapidly than increases in mean sea levels. Our conclusion is that while there is evidence of changes in storminess with climate change, quantification of these changes for Copenhagen is not possible at present. In this study, we assume that storm surge risk is changed only through sea level rise and not through changes in storminess. We note that this could lead to an underestimation of future risk and

\footnotetext{
${ }^{4}$ Bengtsson et al. (2006) note an increase in the frequency of the most intense storms in Europe (despite seeing no significant increase globally), whilst Lozano et al. (2004) finds an eastward shift in the most intense storms over the British Isles (as well as a general increase in intensity).
} 
a full study for Copenhagen should consider a broader range of scenarios for future storminess.

\section{Insured exposure analysis}

The exposure is the measure of the population and the assets that would be affected by a flood in absence of flood protection. The exposure to coastal flooding in Copenhagen was calculated based on the area of land that would be inundated with different sea levels and on the population and asset distribution. Because of constraints on data availability, only insured assets are considered in this section; however, as all residential homes, personal property, businesses, and commercial property are insured publicly against flood (1991 Flood Act) we assume that the insured residential, commercial and industrial exposure is roughly equal to the total exposure for these sectors. Our exposure estimates do not however include public assets, such as transport, energy and water infrastructures and government buildings. These assets will be included in loss estimates in Section 4.

Population data for Copenhagen was obtained from Landscan 2002 (constrained within metropolitan extent limits) and verified against UN 2005 population data (UN 2005). The metropolitan area was defined using postcode information (from $\mathrm{RMS}^{5}$ data). Data on residential, commercial and industrial exposure was based on the industry exposure data from the RMS European Winterstorm Model. The exposure of population and asset value to coastal inundation was modelled through geographical mapping onto a Digital Terrain Model (DTM). The DTM was generated from the $90 \mathrm{~m}$ (horizontal resolution) elevation database of the Shuttle Radar Topography Mission (SRTM). Exposures by elevation were then extracted from the DTM at $1 \mathrm{~m}$ vertical intervals. Finally, cumulative exposures were calculated for each of the sea level events, through interpolating linearly between the vertical intervals. At the pixel level, the SRTM elevation data can have errors of up to $10 \mathrm{~m}$, which is large compared with sea level changes we are considering. These errors, however, are much lower in flat areas, where flood risks are concentrated, and have a large long-wavelength component (at the continent scale) that is constant over our analysis area and is therefore not a problem when investigating local elevation differences (see a complete analysis in Rodriguez et al. 2005). In the present analysis, moreover, elevation maps were created by analysing continuous contours iso-lines in the dataset, thereby smoothing out much of the short-wavelength errors. This means that this dataset is adequate for aggregate economic cost-benefit analysis at a city-level, as shown here, to assess the need for protection and other adaptation measures. However, given the errors inherent in individual pixels, this dataset is not adequate for localised engineering decisions, e.g. the design of sea walls and dykes. Such analyses would require higher-resolution exposition and elevation datasets.

The exposure analysis shows that around $2 \%$ of the population (21,907 people) live below an elevation of $1 \mathrm{~m}, 4 \%$ (44,446 people) below an elevation of $2 \mathrm{~m}$ and $13 \%$ (151,859 people) below an elevation of $5 \mathrm{~m}$ above sea level. Figure 3 demonstrates that the most exposed areas of the city lie on the island of Amager

\footnotetext{
${ }^{5} \mathrm{RMS}$ is Risk Management Solutions, Inc., a private business that provides products, services, and expertise for the quantification and management of catastrophe risk.
} 

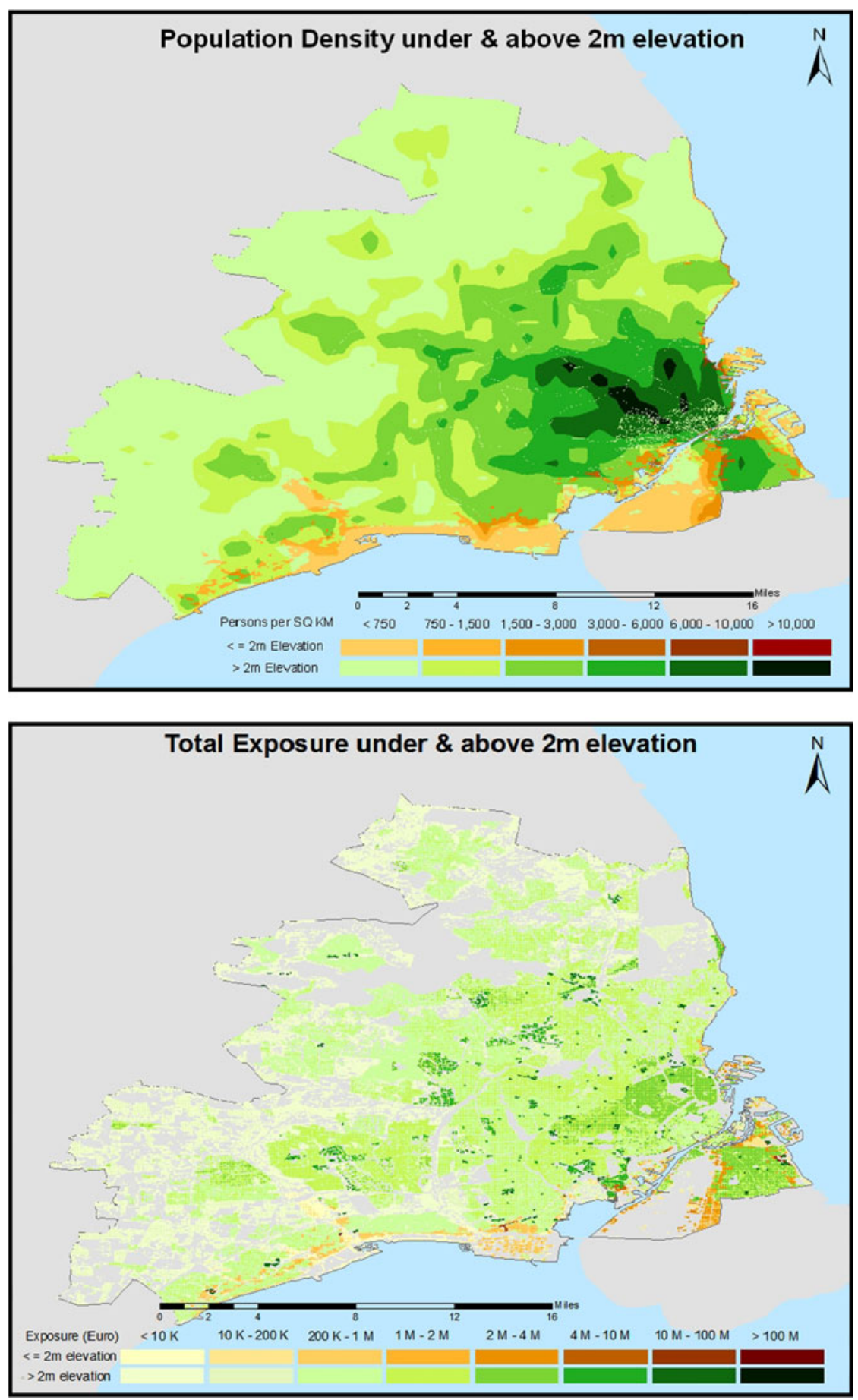

Fig. 3 Population density (top panel) and total exposure (bottom panel) situated in areas with an elevation below (orange) and above (green) $2 \mathrm{~m}$ elevation above sea level 
and along the coastline of the larger island of Zealand (particularly to the South). The most densely populated area of Copenhagen, to the West of the centre, is at relatively low vulnerability, as it lies away from the coast. In terms of Total Insured Value (TIV), the industrial sector is most exposed and is vulnerable to even limited increases in sea levels due to its location by the coast; around 24\% (EUR $1.7 \mathrm{bn}$ ) of the industrial TIV across Copenhagen lies below an elevation of $1 \mathrm{~m}$, and $18 \%$ (EUR 1.3bn) lies below $0.5 \mathrm{~m}$. Most of this lies along the facing coasts of Zealand and Amager, and on the southern coast. A sea level $4 \mathrm{~m}$ above the current normal level would expose half of the industrial TIV. However, the industrial asset class is relatively small in insured value terms compared with the Residential and Commercial classes. The Residential asset class becomes the largest contributor to exposed TIV for sea levels of more than $1 \mathrm{~m}$ above current mean level. Agricultural total insured value is also relatively low, unsurprising for an urban area.

Table 1 summarizes the insured asset exposure (or TIV) at different levels of elevation relative to current mean sea level. The table distinguishes between the structure exposure (i.e. the buildings themselves) and the content exposure (i.e. what is in the buildings). These values are calculated using the current economic situation in Denmark. Of course, socio-economic and population changes will influence exposure in the future. According to the 2005 UN population growth scenario, the Danish population should increase by $2 \%$ by 2070. Assuming that the Danish urbanisation rate will increase from $86 \%$ today to $90 \%$ in 2070 and that all Danish cities will grow at the same rate, the Copenhagen population would increase by $7 \%$ by the 2070's. This population increase is small and it is unlikely that the global risk profile of the city would change substantially due to population growth. Over the long term, however, risk-oriented land-use policies can influence risk levels: the replacement of old building or industrial property can be prohibited or discouraged in at-risk areas, and new developments can be favoured in less-exposed locations. In this analysis, however, it is assumed that no such policy is implemented, and that urbanized areas will basically remain unchanged in the future. However, it is expected that existing properties in these unchanged urbanized areas will be replaced through normal processes, increasing in value in response to economic growth.

Based on the OECD economic scenario for economic growth in Denmark, indeed, all exposed values could be multiplied by 3.5 due to GDP growth. This OECD

Table 1 TIV exposure for various elevation layers (elevation with respect to current mean sea level, numbers in millions Euros)

\begin{tabular}{|c|c|c|c|c|c|c|}
\hline \multirow[t]{2}{*}{ Elevation range } & \multicolumn{2}{|c|}{ Residential } & \multicolumn{2}{|c|}{ Commercial } & \multicolumn{2}{|l|}{ Industrial } \\
\hline & Structure & Content & Structure & Content & Structure & Content \\
\hline $0-0.5 \mathrm{~m}$ & 640 & 270 & 236 & 71 & 393 & 933 \\
\hline $0.5-1 \mathrm{~m}$ & 737 & 311 & 699 & 210 & 119 & 283 \\
\hline $1-1.5 \mathrm{~m}$ & 691 & 292 & 495 & 427 & 84 & 199 \\
\hline $1.5-2 \mathrm{~m}$ & 1,735 & 732 & 841 & 554 & 165 & 390 \\
\hline $2-2.5 \mathrm{~m}$ & 1,183 & 499 & 534 & 436 & 105 & 249 \\
\hline $2.5-3 \mathrm{~m}$ & 2,476 & 1,045 & 377 & 657 & 117 & 276 \\
\hline $3-3.5 \mathrm{~m}$ & 1,567 & 661 & 725 & 217 & 65 & 155 \\
\hline $3.5-4 \mathrm{~m}$ & 2,768 & 1,168 & 742 & 223 & 68 & 162 \\
\hline $4-4.5 \mathrm{~m}$ & 1,507 & 636 & 498 & 149 & 62 & 148 \\
\hline $4.5-5 \mathrm{~m}$ & 2,514 & 1,061 & 102 & 307 & 88 & 209 \\
\hline
\end{tabular}


scenario, however, is only one of many possible scenarios given the large uncertainties in future socio-economic and population changes. To take into account these uncertainties, it is common to carry out sensitivity analyses, using many scenarios to investigate how results are sensitive to socio-economic drivers and hypotheses. While increased economic growth increases exposure, it also increases resilience in the affected economy, making it more capable to deal with disasters and reconstruction. The most relevant figures to assess disaster seriousness, therefore, are the exposed population - in absolute numbers - and the ratio of exposed asset value to total asset value. These figures are likely to increase only marginally in the future in Copenhagen, as it is unlikely that the population of Denmark will increase rapidly in the future, and given that the urbanization process is almost complete in this country. As a consequence, no large change in socio-economic drivers is expected to modify our findings. For this reason, the rest of this report will disregard the role of socioeconomic trends on flood risks, to focus on the effect of climate change on the city as it is today, with current population and assets.

\section{Flood losses analysis in Copenhagen}

There is a complex link between exposure to high sea level and the destruction and losses caused by such episodes. First, a building that is affected by a flood is not completely destroyed. Thus, direct losses caused by an event are usually significantly lower than the exposure to this event. Second, high sea levels are frequent events, and cities are protected against the most frequent of them. In Sections 4.1 and 4.2, we will first assume that the city is not protected and assess potential losses. This analysis provides the information required to design an optimal protection strategy. The actual protection of the city today, and the actual current flood risks in Copenhagen, are considered in Section 4.3. Moreover, as outlined in Section 3, considering the limited urban changes that are expected in the future in Copenhagen, this analysis is based upon Copenhagen as we find it today (i.e. an unchanged city over time).

\subsection{Assessing direct losses in absence of protection}

Direct losses here are defined as the repair and replacement cost of damaged buildings and equipment. Of course, this cost is only a fraction of total cost, and additional components of total cost (e.g., production loss, job loss) are investigated later in the study. We estimate direct losses for each asset class at a given level of sea level through combining the exposure information given in Table 1 with pre-defined vulnerability curves. Vulnerability curves give the level of damage as a function of flood depth, where the level of damage is defined as the ratio of damages to the total exposure ${ }^{6}$. Note that these estimates do not take into account important

\footnotetext{
${ }^{6}$ Illustrative vulnerability curves have been provided by Risk Management Solutions. It should be noted that early warning, disregarded here, can help reduce content losses. For instance, valuable equipment and furniture can often be saved by households if the event is forecasted early enough. The vulnerability data used here, however, take into account the average effect of early warning and mitigation measures. In the future, improvements in the ability to forecast storms and storm surges may reduce content losses significantly.
} 
Fig. 4 Direct losses as a function of sea level with respect to current mean level, in absence of protection

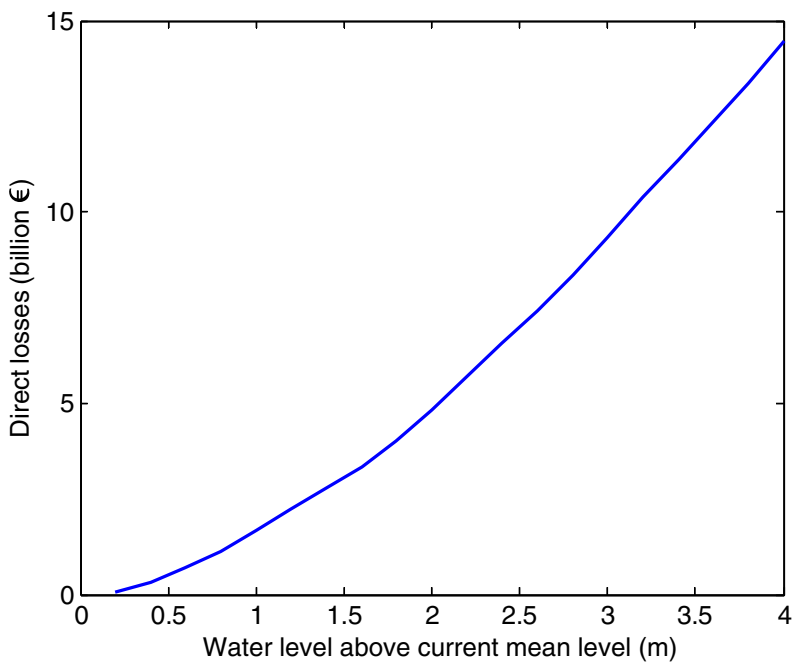

local parameters of flooding: local differences in water level, water velocity, flooding duration, various building types in different areas, etc. Taking into account these factors would require explicitly modelling the water flows at high-resolution; such detailed analyses would be required for informing local engineering decisions.

Direct losses to non-insurable assets, such as public infrastructure, must also be included but little information is available; to make an approximation, we draw on the well documented consequences of the Katrina landfall in New Orleans. According to the Louisiana Recovery Authority, ${ }^{7}$ the Katrina losses were distributed in the following way: residential homes and personal property (USD 27-35 billion); businesses and commercial property (USD 25-29 billion); Infrastructure including roads, bridges, utilities (USD 15-18 billion); state facilities and public/private education and health care facilities (USD 6-8 billion). As with Katrina losses, we will assume, therefore, that uninsurable losses (infrastructure plus state facilities) represent about $40 \%$ of insurable losses (residential homes and personal property plus business and commercial). This estimate is also consistent with other studies in the UK. ${ }^{8}$

Figure 4 shows the direct loss estimates (insured + uninsured), as a function of the water level in Copenhagen, and in absence of protection infrastructures. Using this information coupled to the earlier storm surge return-period analysis (Fig. 2), and assuming that sea level rise only shifts water levels, it is possible to estimate the return-period of levels of direct losses for different magnitudes of sea level rise (in absence of protection); shown in Fig. 5. Such statistical loss information forms the basis of a risk-based cost-benefit analysis for adaptation. Figure 5 shows that in the current situation, a 1-in-100 year event would cause direct losses of about EUR 3 billion. With $50 \mathrm{~cm}$ sea level rise, a 1-in-100 year event would cause direct losses amounting to about EUR 4.8 billion; i.e. a $55 \%$ increase on the present situation.

\footnotetext{
${ }^{7}$ http://www.lra.louisiana.gov

${ }^{8}$ See, e.g., Penning-Rowsell et al. (2002).
} 
Fig. 5 Direct losses caused by the flooding of Copenhagen, as a function of the event return time, and for various level of sea level rise

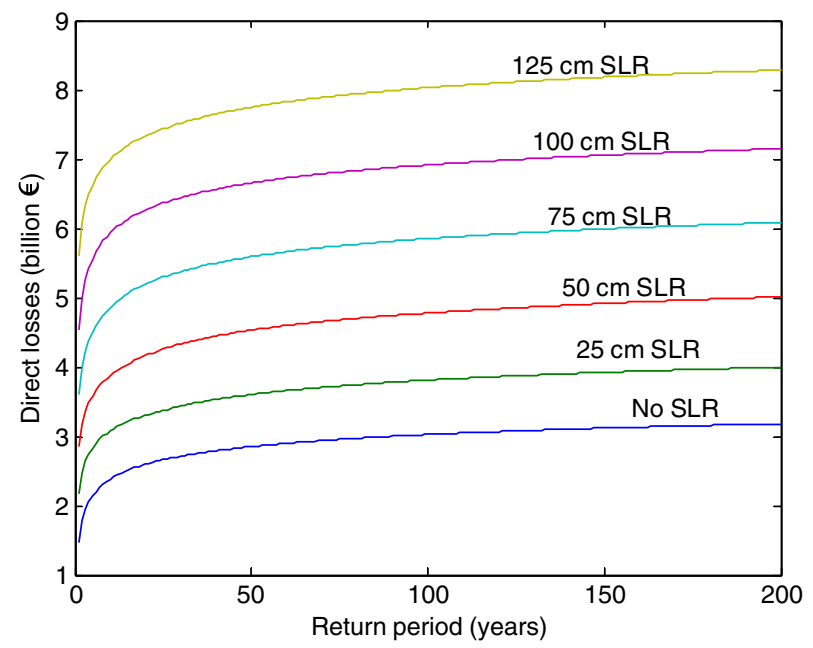

The figure demonstrates that, without protection, sea level rise increases the risk of flooding significantly.

\subsection{Assessing total losses in absence of protection}

Direct losses are only a fraction of total costs due to a disaster. Several authors have suggested that the direct costs, generally evaluated by insurance companies, may be poor proxies of overall costs, particularly in the case of large-scale events (Tierney 1995; Pielke and Pielke 1997; Lindell and Prater 2003; Hallegatte et al. 2007; Hallegatte 2008). Direct costs can be magnified by: (i) the spatial or sectoral diffusion of damages into the wider economic system over the short-term (e.g. through disruptions of lifeline services) and over the longer term (e.g. sectoral inflation due to demand surge, energy costs, company bankruptcy, larger public deficit, or housing prices); (ii) the responses to an economic shock (e.g. loss of confidence, change in expectations, indirect consequences of inequality deepening); (iii) financial constraints impairing reconstruction (e.g. low-income families cannot finance rapidly the reconstruction of their home); and (iv) technical constraints slowing down reconstruction (e.g. availability of skilled workers, difficulties in equipment and material transportation, difficulties in accommodating workers).

In this section, we estimate the total costs of flooding in Copenhagen in terms of lost consumption. This cost is equal to the sum of direct and indirect costs. Indeed, the direct costs is both (i) the reparation or replacement cost (at the pre-event price level) of the assets that have been damaged or destroyed; and (ii) the portion of the produced value-added that has to be dedicated to reconstruction instead of normal consumption. The indirect cost is the reduction in production of goods and services across the economy due to the disaster. The sum of what is not produced and what is produced but cannot be consumed is equal to the lost consumption, i.e. the cost of the disaster.

Indirect costs include business interruption in the disaster aftermath, production losses during the reconstruction period, and service losses in the housing sector. For 
example, if a EUR 1 million production facility is destroyed and immediately rebuilt, the total loss is EUR 1 million; however, if reconstruction is delayed by 1 year, the total loss is the sum of the replacement cost (direct cost) and of the value of 1 year of lost production (indirect cost). For housing, the total cost of an extreme event that destroys a house is equal to the replacement cost of the house plus the value attributed to lost housing services during the number of months or years it takes to rebuild it. ${ }^{9}$ The value of such production losses, in a broad sense, can be very high in some sectors, especially when basic needs are at stake (housing, health, employment, etc.). This distinction can also be represented in terms of stock (direct) and flow (indirect) losses.

Indirect losses are difficult to estimate, but must be included to ensure a fair cost-benefit analysis of protection for infrastructures or mitigation actions. Here, the Adaptive Regional Input-Output (ARIO, see Hallegatte 2008) model is used to assess these losses in the Copenhagen region. The model is based on input-output (IO) tables and a hybrid modelling methodology, in the spirit of Brookshire et al. (1997). This dynamic model takes into account changes in production capacity due to productive capital losses and adaptive behaviour in disaster aftermaths. It should be noted that the uncertainty in results is still large, and therefore, results should be interpreted as indicative of the scale of potential damages. The model takes into account (i) the propagation of effects among sectors of reduced production due to disaster damages; (ii) the propagation of effects among sectors of reduced demands due to disaster damages; (iii) the large demand in the construction sector due to reconstruction needs; (iv) the economic-agent behaviours to cope with disaster consequences and substitute non-available supplies (e.g., by increasing their production when demand is large, or by finding alternative suppliers when the original ones cannot produce); (v) the limitations in resource movement between sectors (e.g., the construction sector cannot grow instantaneously by hiring workers from other sectors; it is limited by the availability of qualified workers); (vi) the economic interactions with regions outside the affected regions (through imports and exports). Importantly, the model is dynamic, with a 1-month time step, and reproduces the whole reconstruction pathway, assuming that the economy will eventually return to its initial situation. ${ }^{10}$ Also, impacts outside the Copenhagen region are not assessed, because these impacts are distributed over a large number of economic actors, and are therefore small (often negligible) on a per capita basis.

The ARIO model is calibrated for the Copenhagen region ("The Capital Region of Denmark") using macroeconomic data from StatBank Denmark. The Danish economy has eight main sectors: (1) agriculture, fishing and quarrying; (2) manufacturing; (3) electricity, gas and water supply; (4) construction; (5) wholesale and retail trade; hotels, restaurants; (6) transport, post and telecommunication; (7) finance and business activities; (8) public and personal services. From the Danish Input-Output tables, a regional IO table for the Copenhagen region is built using simple rules

\footnotetext{
${ }^{9}$ There may also be gains to be accounted for, arising from the fact that, after reconstruction, assets are more recent than before the event. Considering infrastructure, production capital and housing, however, this gain is of second order.

${ }^{10}$ For instance, businesses are assumed to lose clients and market shares over the short-term, but clients are assumed to return eventually to their original suppliers over the long-term, restoring original market shares.
} 


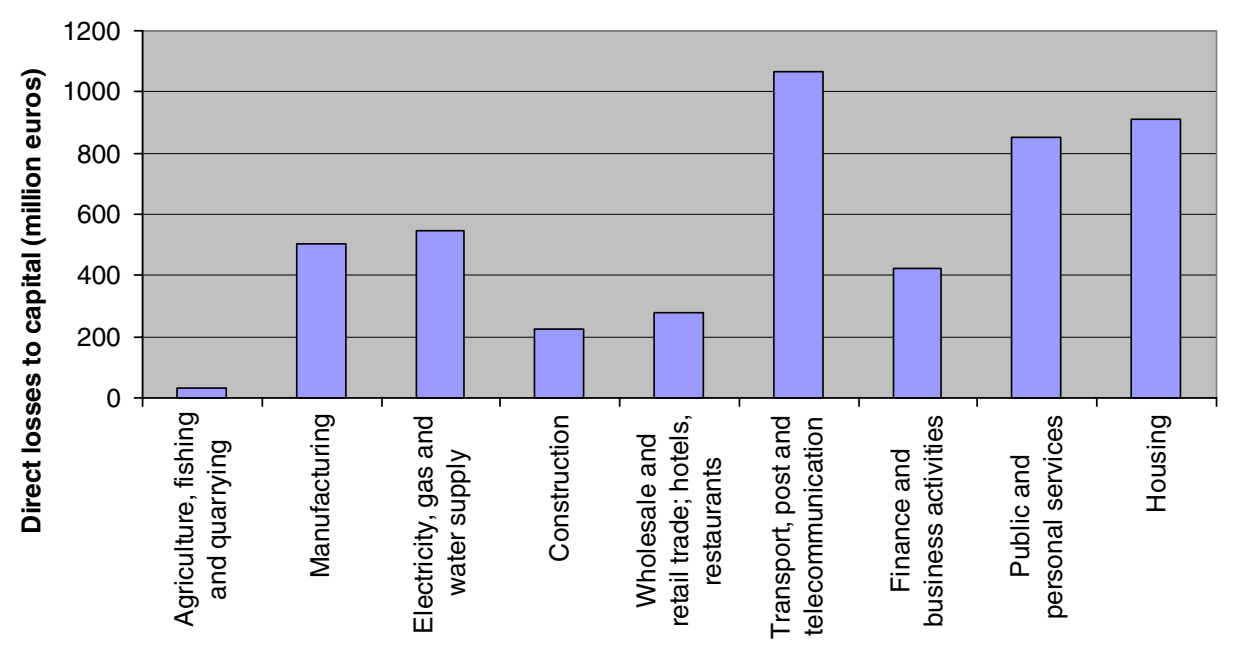

Fig. 6 Estimated sector-per-sector losses due to a sea level $2 \mathrm{~m}$ above current sea level, in absence of protection

based on the size of each sector in this region (see Hallegatte 2008 for details). The input to the model is the sectoral distribution of direct losses due to flooding. These are calculated from the analyses of Section 4.2 with a number of assumptions: (i) residential losses affect only households; (ii) industrial losses are assumed to affect sectors 2, 3, 4, and 6 (per above) and are distributed among these sectors proportionally to the value added by each sector; (iii) commercial losses affect sectors 5,7 and 8 , also proportionally to sector value added; and (iv) the uninsured additional losses-equal to $40 \%$ of insured losses-are distributed between utilities (35\%), transportation $(35 \%)$, and public and personal services $(30 \%)$. Figure 6 provides an example of the sectoral distribution of direct losses for a $2 \mathrm{~m}$ sea level above current level (corresponding to roughly to the 100 -year event with a $50 \mathrm{~cm}$ sea level rise).

\subsubsection{Case study: $2 \mathrm{~m}$ sea level rise}

In this subsection, we present the calculation and analysis of indirect losses for the case of a $2 \mathrm{~m}$ increase in sea level above present-day levels; this would correspond, for example, to a $50 \mathrm{~cm}$ increase in sea level and a 1-in-100 year storm surge event. Figure 7 shows the change in value added (VA) across 8 sectors as a function of time. Figure 8 shows the job losses in these sectors 3 and 12 months after the event. Clearly most sectors show a reduction in VA, with the exception of the construction and, to a lesser extent, manufacturing sectors. Reconstruction drives an increase in VA in these two sectors.

In the early period following a storm surge, the losses and gains in VA are estimated to roughly balance each other, however a total of 7,500 jobs are lost in the 3 months after the disaster. The sectors most heavily impacted in the aftermath of the event are: (1) wholesale and retail trade, hotels and restaurants, (2) finance and business activities, (3) transport, post and telecommunication, and (4) public and personal services. Previous studies applying ARIO to the case of Katrina (Hallegatte 2008) showed that employment losses in these sectors with many small businesses 
Fig. 7 Sector per sector change in value added (in \%) during the reconstruction period, after a high sea level event $2 \mathrm{~m}$ above current sea level, in absence of protection

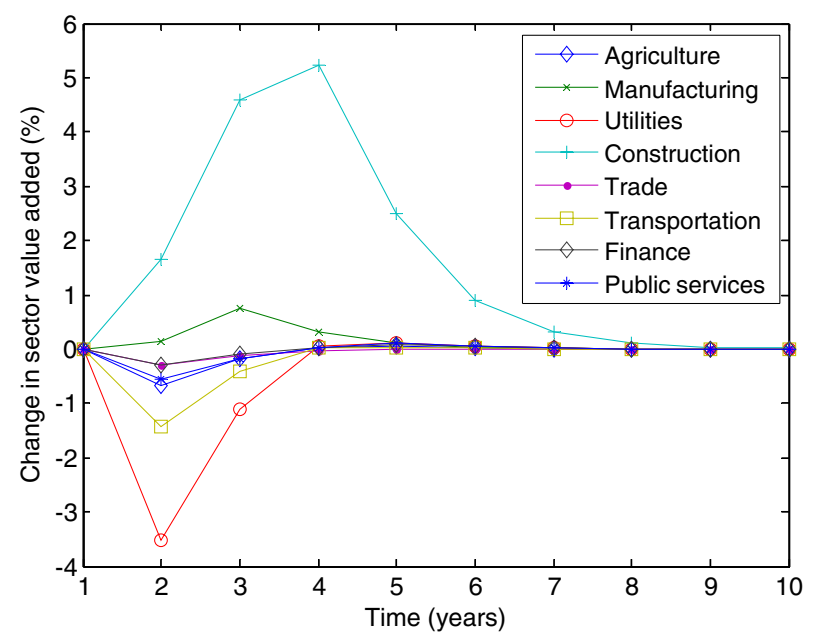

(e.g. personal services) were underestimated, as the model is not able to account for bankruptcy and business closure. This suggests that public aid should be directed toward these sectors in disaster aftermath.

Over time the net VA loss for the region is actually negative; that is, there is an increase in economic VA in the affected region. This is driven by the mobilization of unused resources and the transfer of reconstruction resources from outside the region, and has a positive effect on the local economy as it creates jobs and income. One year after the event, the reconstruction is underway and the construction and manufacture sectors are a net creator of jobs, while lost jobs in other sectors are reduced by more than $50 \%$. Nevertheless, the disaster still leads to 500 lost jobs at the aggregate level 1 year after the shock. Since there is a gain in VA, this analysis suggests that the shock would not be detrimental at the macroeconomic

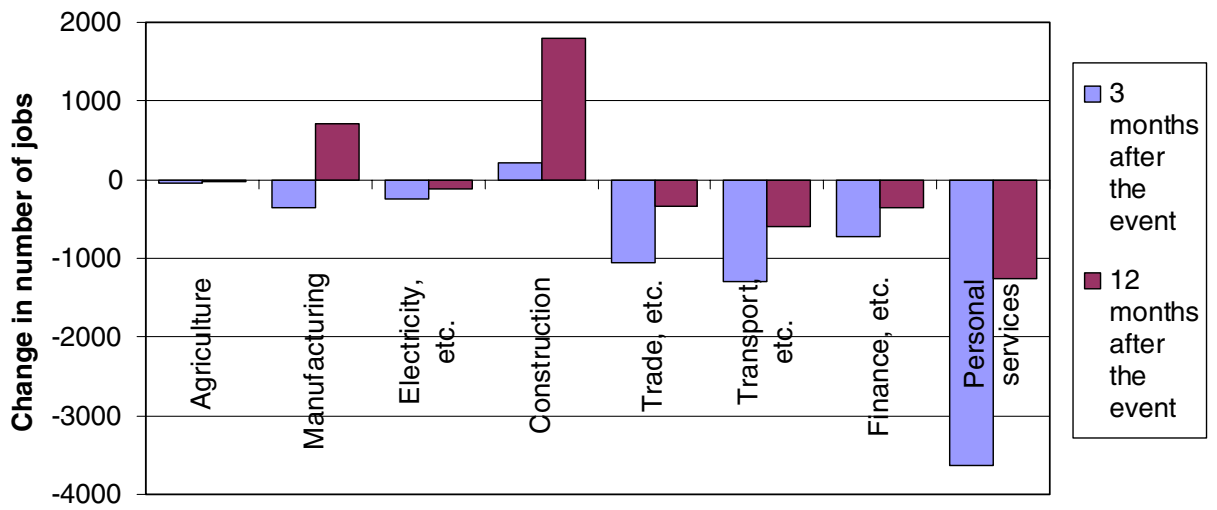

Fig. 8 Change in number of job per sector (positive is for additional jobs, negative is for job losses) due to the $2 \mathrm{~m}$ event, 3 months and 12 months after the event, in absence of protection 
scale, however it could still be very problematic at the sector level (e.g., for workers of the personal service sector).

Over a 10-year period, the total VA gain for the event is EUR 95 million (it should be noted however, that this additional production is used to repair and reconstruct what has been damaged by the flood, and should not be considered as additional consumption). It is also noteworthy that the change in VA becomes negative for large disasters as indirect losses increase non-linearly with direct losses; for example, for a $3 \mathrm{~m}$ event with EUR 8 billion in direct losses, total VA losses shift from being net gains to net losses for the Danish economy as a whole.

The ARIO model is also able to estimate "production loss" in the housing sector; houses and residential buildings provide a service that plays a major role in delivering local well-being. The decrease in housing services because of damaged houses and buildings has, therefore, to be taken into account. For the $2 \mathrm{~m}$ water level case, the ARIO model estimates housing service losses at EUR 260 million; greater than the estimated net gain due to VA increases in manufacturing and construction. The sum of all indirect impacts, therefore, is equal to EUR 165 million.

Two important caveats must be mentioned. Firstly, the model does not reproduce the very first weeks following an event, during which lifeline services are disrupted and emergency operations impair the functioning of the economic system. The corresponding additional production losses are assumed to be one order of magnitude lower than the production losses estimated here. Secondly, the model assumes that all reconstruction costs are covered by commercial, household or automobile insurance, and households do not need to reduce consumption to pay for the reconstruction. This assumption is likely to be fairly accurate for Denmark, but is unlikely to hold for many other locations (see the case of Mumbai in Ranger et al. 2011, in this issue).

\subsubsection{Analysis of the link between direct losses and total losses}

Indirect economic losses are found to be significant in this analysis and are strongly nonlinear relative to direct losses. This nonlinearity arises from two factors: firstly, a larger disaster causes larger production losses at a given point in time; and secondly,

Fig. 9 Change in total value added (excluding housing services) as a function of time, for the $2 \mathrm{~m}$ and $4 \mathrm{~m}$ events in Copenhagen, in absence of protection

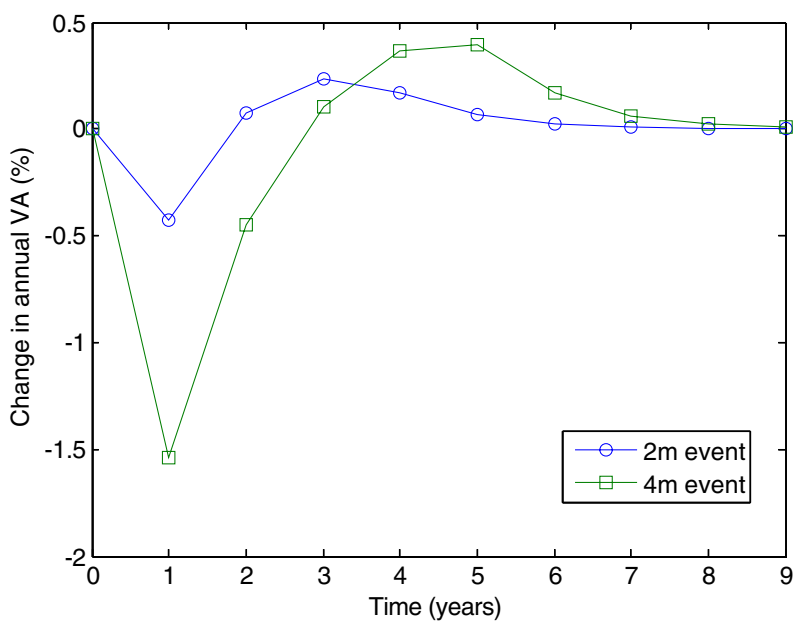


Table 2 Components of the total flood losses, as a function of water level above current mean level, in absence of protection

\begin{tabular}{|c|c|c|c|c|c|c|}
\hline \multirow{3}{*}{$\begin{array}{l}\text { Event sea } \\
\text { level wrt } \\
\text { current } \\
\text { mean } \\
\text { level (m) }\end{array}$} & \multirow{3}{*}{$\begin{array}{l}\text { Direct } \\
\text { losses } \\
\text { (million EUR) }\end{array}$} & \multicolumn{3}{|c|}{ Indirect losses } & \multirow{3}{*}{$\begin{array}{l}\text { Total losses } \\
\text { (direct + indirect) } \\
\text { (million EUR) }\end{array}$} & \multirow{3}{*}{$\begin{array}{l}\text { Lost jobs } \\
\text { after } \\
3 \text { months } \\
\text { (thousands) }\end{array}$} \\
\hline & & \multicolumn{3}{|c|}{ Value added losses (million EUR) } & & \\
\hline & & $\begin{array}{l}\text { Loss in } \\
\text { productive } \\
\text { sectors }\end{array}$ & $\begin{array}{l}\text { Loss in } \\
\text { housing } \\
\text { services }\end{array}$ & $\begin{array}{l}\text { Total value } \\
\text { added } \\
\text { losses }\end{array}$ & & \\
\hline 1 & 1,668 & -58 & 72 & 14 & 1,682 & 3 \\
\hline 2 & 4,837 & -95 & 257 & 162 & 4,999 & 7 \\
\hline 3 & 9,341 & 64 & 682 & 747 & 10,088 & 14 \\
\hline 4 & 14,478 & 517 & 1,446 & 1,964 & 16,442 & 21 \\
\hline
\end{tabular}

a larger disaster leads to a longer reconstruction period and, therefore, production losses last for a longer period. These two factors are illustrated in Fig. 9, which shows the reconstruction dynamics in $2 \mathrm{~m}$ and $4 \mathrm{~m}$ water level cases. In the $4 \mathrm{~m}$ case, VA losses 1 year after the shock exceed $1.5 \%$ of the pre-event level, while they are only about $0.5 \%$ in the $2 \mathrm{~m}$ case. Moreover, total production is back to its initial level 1 year after the shock in the $2 \mathrm{~m}$ case, while it takes 3 years in the $4 \mathrm{~m}$ case. Full reconstruction is almost completed 8 years after the event in the $4 \mathrm{~m}$ case, against only 5 years in the $2 \mathrm{~m}$ case.

Due to additional production in the construction and manufacturing sector, VA losses in the production sectors remain limited or negative, ranging from EUR 95 million for the $2 \mathrm{~m}$ event to EUR 517 million in the $4 \mathrm{~m}$ event. Most indirect losses stem from the housing sector, where delayed reconstruction-due to production capacity constraints in the construction sector-has a large impact. Housing service losses reach EUR 257 million for the $2 \mathrm{~m}$ event and EUR 1.4 billion for the $4 \mathrm{~m}$ event. This type of loss is highly nonlinear, as illustrated by Table 2 and Fig. 10. This figure shows the indirect losses, including housing services, as a function of water level. It shows that, up to the $1.5 \mathrm{~m}$ event (EUR 3.1 billion of direct losses), indirect losses are

Fig. 10 VA losses (productive sectors plus housing sector), as a function of water level above current mean level, in absence of protection

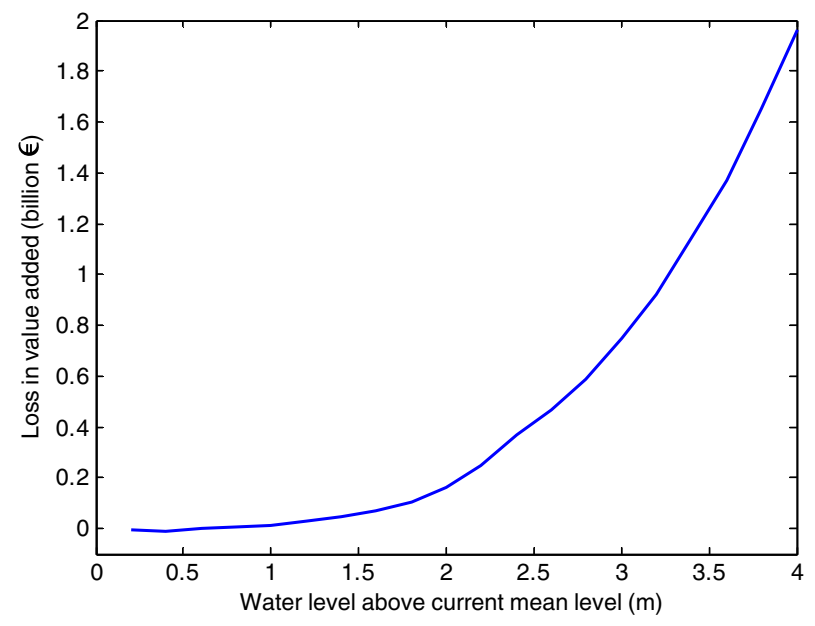


Fig. 11 Total economic losses as a function of sea level above current level, in absence of protection

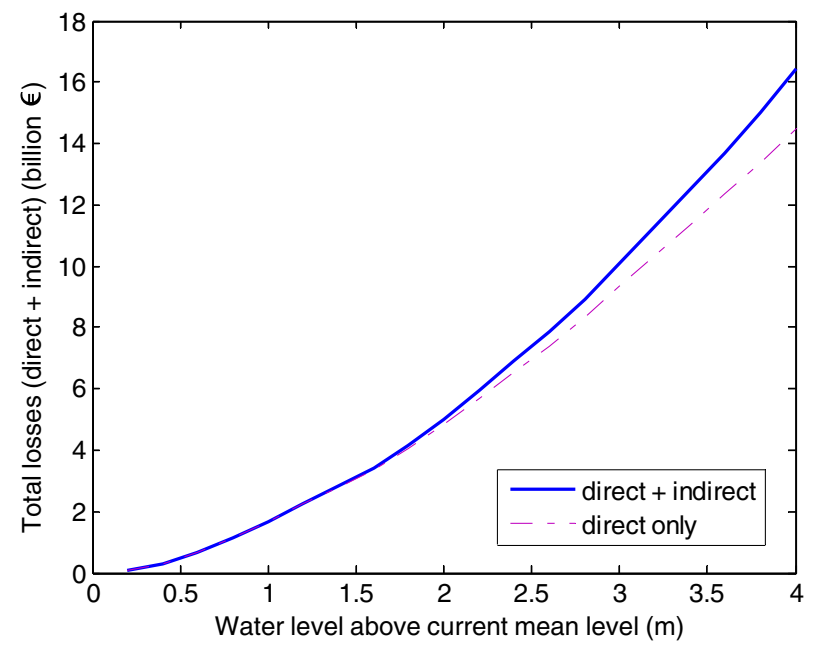

negligible. Above this value, however, they increase rapidly to reach EUR 2 billion in the 4 m event (EUR 15 billion of direct losses).

\subsubsection{Link between sea level and total economic losses in absence of protection}

From the information provided by the ARIO model and the assessment of direct losses due to various sea levels, we can estimate the overall economic consequences due to each of these sea levels. This is provided by Figs. 11 and 12, which shows the total economic losses (direct losses plus production losses plus loss in housing services) and the total job loss 3 months and 12 months after the event, respectively.

Figure 11 shows that indirect losses remain small compared to direct losses for all the events considered here, suggesting that adaptation measures have to focus on direct loss reduction (using dikes or reinforced buildings) rather than on indirect loss reduction (using insurance or support to small businesses).

Fig. 12 Total losses caused by the flooding of Copenhagen, as a function of the rise in mean sea level, and for various event return times, in absence of protection

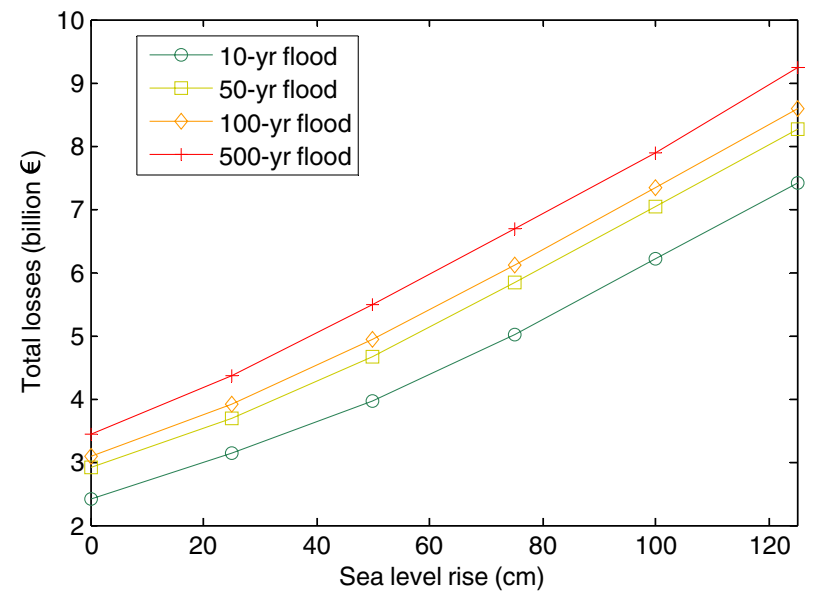


As shown in Table 2, job loss 3 months after the event can reach more than 20,000 jobs for the $4 \mathrm{~m}$ events. Most lost jobs, however, are recreated rapidly, as job loss are always lower than 7,000 1 year after the storm. It should be mentioned that, while the aggregated job totals recover, there are still job losses in some sectors, with totals compensated by job creation in the construction sector. This shift could cause social problems requiring public action, including shortage of qualified workers in the construction sector. Further, short- to long-term structural unemployment among residents in non-construction professions could arise due to skill and qualification mismatches as employment in the other sectors recovers at a slower pace.

From the return level of high water level calculated in Section 2.2, and assuming that the water levels are only shifted by sea level rise, it is possible to calculate total losses as a function of return time. The results, assuming no protection, are reproduced in Fig. 12. For instance, for no sea level rise, the water level with a 50-year return time would cause total losses amounting to EUR 2.9 billion with no protection. With a $50 \mathrm{~cm}$ sea level rise, these losses increase $60 \%$ to EUR 4.7 billion. For the $100-$ year event, losses are estimated at EUR 3.1 billion in the absence of sea level rise, whereas losses also increase $60 \%$, to EUR 5.0 billion with a $50 \mathrm{~cm}$ sea level rise, and $140 \%$ increase to EUR 7.4 billion with a $1 \mathrm{~m}$ SLR.

\subsection{Coastal protection in Copenhagen, residual risks, and future risks}

The previous analysis provides estimates for exposure and loss potentials, information which is needed to design optimal flood protection through cost-benefit analysis or risk management strategies. A typical measure of the risk level is the mean annual loss, which is calculated as the sum of the occurrence probability of all possible events multiplied by the total losses they would cause.

Figure 13 shows an assessment of mean annual losses (direct + indirect) as a function of the protection level, which is assumed uniform in the city, and for several levels of SLR. Our statistical analysis of storm surge considered only surges of more than $80 \mathrm{~cm}$, so protection below this level cannot be assessed. We also assume that an overtopped dike is totally inefficient to control coastal floods. This is oversimplified,

Fig. 13 Mean annual losses, in million of Euros per year, as a function of the protection level, assumed uniform in the Copenhagen. Note: when protection is less than $80 \mathrm{~cm}$ higher than sea level (the horizontal lines in the figure), our methodology is not applicable

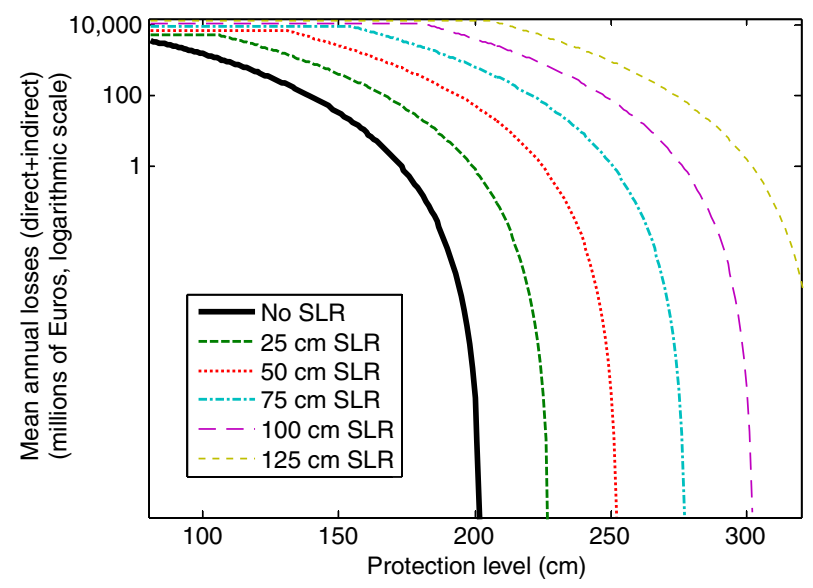


of course, as even an overtopped dike-provided it does not fail completelycan limit the amount of water that enters the city, therefore reducing the flooded area.

The "No SLR" line in this figure shows that Copenhagen is currently easy to protect against storm surges. While annual mean losses can reach several billions of Euros with protection of less than $1 \mathrm{~m}$, they decrease very rapidly with protection height. They are lower than 100,000 Euros per year for $180 \mathrm{~cm}$ protection, and null for protection higher than $202 \mathrm{~cm}$. Interestingly, this rapid decrease in mean annual loss arises from the probability of occurrence, which decreases very rapidly as water level increases, not from the event losses, which are increasing almost linearly with water level. In other terms, this decrease does not arise from the topography of Copenhagen, but from the characteristics of storm surges in its location, i.e. from the fact that the city is protected from the strongest storms by its locality.

Copenhagen has a coastline of about $60 \mathrm{~km}$, and the building cost of $1 \mathrm{~m}$-high dikes is estimated to be about USD 2.5 million per km (Hoozemans et al. 1993). Using this as an assumption, it is possible to estimate the construction cost of coastal flood protection to be a few hundred millions of Euros for the city, for height of less than 2 or $3 \mathrm{~m}$. In particular, in the range of dike heights that are necessary given the sea level rise projections considered here, construction costs are not expected to exhibit strong nonlinearities. Considering the potential flood losses shown in Fig. 13, it seems economically rational to protect the city with very high dikes. Taking into account the uncertainty in the different steps of our analysis, and especially the uncertainty concerning the highest possible storm surges assessed in Section 2.2, it is rationaleven in absence of sea level rise-to protect the city with dikes that are higher than $202 \mathrm{~cm}$.

Figure 13 also shows why it is necessary to have higher protection over time as sea level rises. With $202 \mathrm{~cm}$ coastal protection, the annual mean loss is zero in our analysis with current sea level, but increases to EUR 1 million per year with $25 \mathrm{~cm}$ of SLR, EUR 52 million per year with $50 \mathrm{~cm}$ of SLR, and EUR 4.2 billion per year with $100 \mathrm{~cm}$ of SLR. With $300 \mathrm{~cm}$ protection, mean annual losses are larger than zero only if SLR is larger than $1 \mathrm{~m}$. With $350 \mathrm{~cm}$ of protection, even $125 \mathrm{~cm}$ of SLR does not lead to any losses.

Fig. 14 Illustrative example assuming a homogenous protection at $180 \mathrm{~cm}$ above current mean sea level (in the 'No SLR' and ' $50 \mathrm{~cm}$ SLR' cases). The vertical arrow shows the cost of SLR in absence of adaptation. The horizontal arrow shows the need for adaptation to maintain mean annual losses unchanged

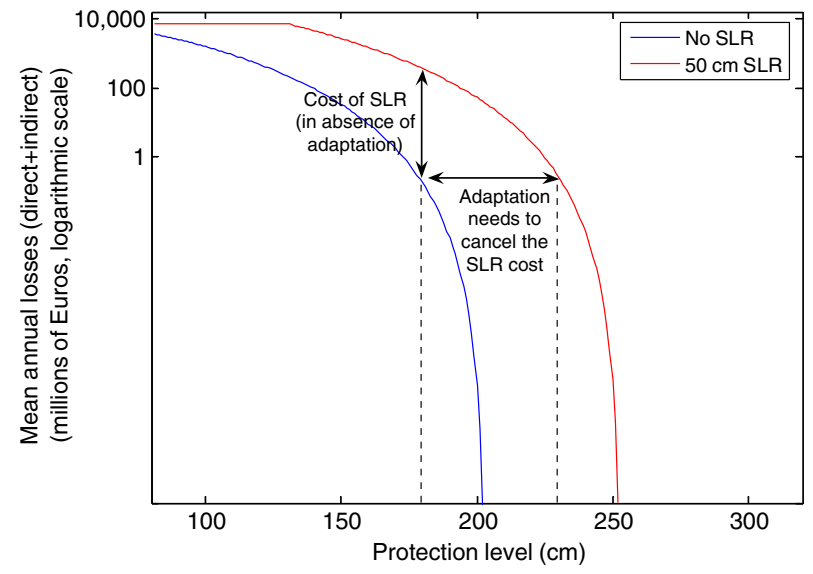


In theory, this figure also allows the comparison of the impacts of sea level rise (in absence of adaptation) and the cost of adaptation (to cancel all impacts) for various amplitudes of sea level rise. This is shown in Fig. 14, which is identical to Fig. 13, but assumes as an illustration that the city is homogenously protected by dikes at $180 \mathrm{~cm}$ above current mean sea level. In this figure, the vertical arrow shows the cost of $50 \mathrm{~cm}$ of SLR, which is the increase in mean annual losses due to a $50 \mathrm{~cm}$ SLR in absence of adaptation (i.e. with no change in the $180 \mathrm{~cm}$ protection level). The horizontal arrow shows the need for adaptation, i.e. by how much the protection level should be increased to maintain unchanged the mean annual losses due to coastal floods. Using dike cost estimates, this need for adaptation can be translated into adaptation costs. This figure, therefore, shows both the cost of SLR in absence of adaptation, and the cost of adaptation to cancel SLR impacts. These cases are two specific options, but other possibilities exist: for instance, one can decide to upgrade protection so that annual mean losses are reduced compared with the current cases (i.e. to do more than adaptation). Regardless, this figure can be used to carry out cost-benefit analysis of coastal protection upgrades in a climate change context.

Of course, the present uncertainty on sea level rise makes the use of these results more difficult. Figure 14, however, also allows the assessment of the potential cost of ill-adaptation, be it due to sea level rise underestimation (i.e. a too low protection

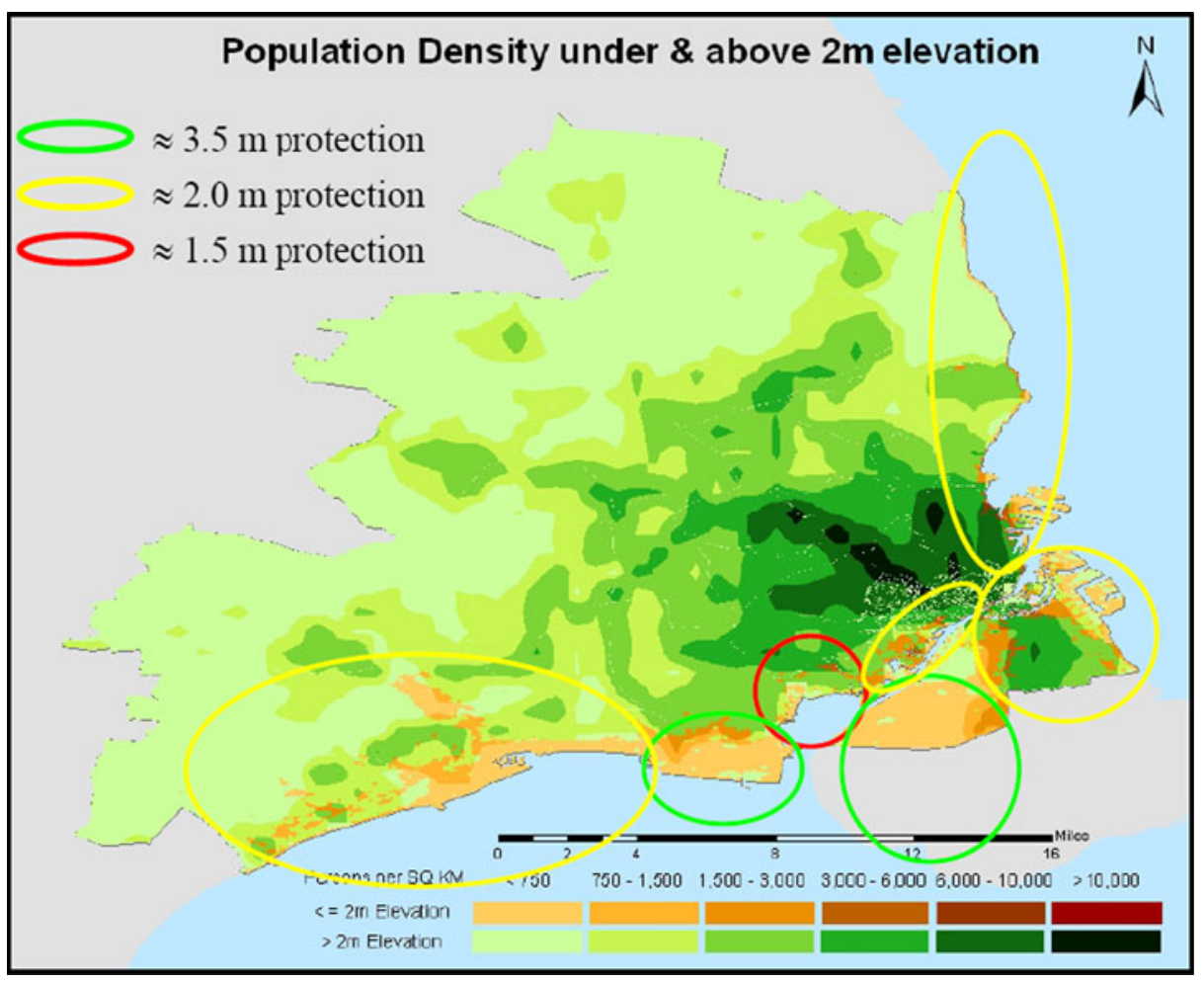

Fig. 15 Population density under and above $2 \mathrm{~m}$ elevation, and coastal protection, indicated by colored ellipsoids (green for $3.5 \mathrm{~m}$ protection; yellow for $2.0 \mathrm{~m}$ protection and red for $1.5 \mathrm{~m}$ protection) 
level and too high mean annual losses from floods) or overestimation (sunk costs due to overinvestment is too large dikes). In the current situation in Copenhagen, it is very likely that the cost of underestimation would be much larger than the cost of overestimation, because protection construction costs have a large fixedcost component while mean annual losses for floods soar rapidly when protection is insufficient. In a risk management strategy, therefore, it seems preferable to consider a pessimistic scenario in adaptation design and land use planning.

Information about Copenhagen on existing protection suggests that the city is very well protected against storm surges. This is consistent with the results of our analysis. First, in the Copenhagen city centre and in the harbour, quays are at more than $2 \mathrm{~m}$ above current sea level. Considering that we estimate the maximum possible storm surge in the current climate at $2 \mathrm{~m}$ (Section 2.2), this protection level suggests that the historical centre-where population density is very high - is not at risk of coastal floods today. In locations that are at-risk according to Fig. 3, protection is present in the form of dikes (see Fig. 15). Considering these protection levels, it seems that Copenhagen is very well protected from coastal flood risk, and even in many places over-protected (e.g., western part of Amager island). As a consequence, even a large amount of sea level rise could be managed by the current protection system. Only a few areas could be affected by storm surges with the current sea level (e.g., Hvidovre) and with higher sea levels (e.g., historical centre of Copenhagen and the harbour). In these areas, protection will have to be upgraded to prevent coastal flood risk from increasing rapidly across the ranges of sea level rise considered here. The concerned coastline segments are relatively limited but include important locations (e.g., the harbour and the city historical centre).

\section{Conclusions}

Our analysis concludes that Copenhagen is not highly vulnerable to coastal flooding today due to its high standards of defence and is unlikely to become so in the future. In the absence of protection, potential losses would nevertheless increase significantly over time. For instance, the total losses (direct and indirect) caused by a present-day 100-year storm surge event, at $150 \mathrm{~cm}$ above normal sea level, are estimated to reach EUR 3 billion with no protection. In the aftermath of such an event, thousands of jobs would be lost and thousands would be created in the construction sector. Other types of impact have been disregarded here, but may also be important (e.g., casualties, illness, psychological trauma, disruption of social networks, loss of national competitive strength and market positions, loss of cultural heritage, city attractiveness, etc.). Even with the relatively narrow set of economic impacts considered here, the reconstruction process would last several years and cause a significant shock to the local and the national economy.

In the absence of protection, future sea level rise would significantly increase flood risks beyond this level. For instance, with $25 \mathrm{~cm}$ of mean sea level rise (SLR) total losses caused by a future 100-year event would rise from EUR 3 billion to EUR 4 billion, to EUR 5 billion with $50 \mathrm{~cm}$ of mean SLR, and to almost EUR 8 billion with $100 \mathrm{~cm}$ of SLR. The timescale of these increases in losses cannot be determined, because of uncertainty in future sea level rise. Indeed, in the most optimistic scenarios (low emission, low climate sensitivity, low response of sea level), 
SLR should not exceed $25 \mathrm{~cm}$ by the end of this century. In the most pessimistic IPCC scenario, SLR would reach $25 \mathrm{~cm}$ in 2050 and up to $60 \mathrm{~cm}$ in 2100 . In alternative scenarios (e.g., Rahmstorf 2007; Hansen 2007), SLR could exceed 1 m by 2100.

Assessing the consequences of one event (i.e. the 100-year event) is not enough to assess aggregate risk across time. A typical measure of the risk level is the mean annual loss, which is calculated as the sum of the occurrence probability of all possible events multiplied by the total losses they would cause and is equal to the expected value of annual flood losses. The mean annual loss takes into account all possible storm surges, and depends on the protection level. As extreme sea level events (referred to as "storm surge events") are not particularly high in Copenhagen, the city is relatively easy to protect with dykes and sea walls and the residual risk is low: while annual mean losses can reach several billions of Euros with protection of less than $1 \mathrm{~m}$, they decrease very rapidly with protection height. They are lower than 100,000 Euros per year for $180 \mathrm{~cm}$ protection, and null for protection higher than $2 \mathrm{~m}$.

The construction cost of a coastal flood protection system for Copenhagen is estimated to be a few hundred million Euros, but additional costs have to be taken into account. Additional market costs include the functioning of the harbour, dike maintenance, drainage and pumping infrastructures. Non-market costs include aesthetic considerations and city attractiveness. For very large increases in sea level, these costs may become significant and will need to be balanced against the benefits of "hard" protection.

Considering the potential flood losses and the protection cost, it would be a rational decision to protect the city with very high dikes. Information about Copenhagen's current protection infrastructure against high sea levels suggests that the city is actually very well protected against possible storm surges. In some locations, current protection appears to be much higher than the largest possible event (e.g., Amager Island), and can thus protect the city against storm surges, even with significant sea level rise in the future. In other locations, defence upgrades will be necessary with sea level rise to maintain flood risk near zero. The concerned coastline segments are relatively limited but include important locations (e.g., the harbour and the city historical centre). It will be necessary to anticipate the need for these investments to implement them in due time. Uncertainty about future sea level rise makes it impossible to predict today when exactly these improvements will be needed, but risk is already increasing in the least well defended locations (e.g., Hvidovre).

Because flood exposure will increase regardless of the protection level, the consequence of protection failure will increase with sea level rise. Faultless maintenance will, therefore, become even more crucial than today. Also, since failure is always possible, it will be necessary to improve emergency plans, early warning and evacuation schemes, and disaster preparedness and organization. Because protection failure is always possible and because dike maintenance is costly and involves significant non-market costs, physical protection and preparedness should be complemented with land-use and urbanization plans that make sure additional people and assets are not put at unacceptable level of risk.

Finally, past experience demonstrates that the retrofit of coastal defence structures is a lengthy process requiring forward thinking and planning. Land-use and urbanization plans take even longer to have a significant impact on risk levels. It is thus necessary to start thinking about long-term adaptation in coastal cities 
today, even if the risks of climate change are not imminent. All planning and new infrastructure investments must take account of the risk over the entire lifetime of the investment to reduce unnecessary capital replacement costs. Because of climate change and sea level rise uncertainty, anticipating requires to build defences in a way that allows for flexibility, taking into account the uncertainties in projections and making it possible to upgrade them if sea level rise is larger than expected.

The analysis carried out here has several caveats which are important to highlight when considering these results. The assessment of economic impacts associated with sea level rise and coastal flooding has been simplified in several ways. In particular, the analysis treats built infrastructure vulnerability very roughly. Flood duration and water velocity are also not taken into account in loss assessment, and flood defences are not explicitly modelled and the consequences of overtopping are not represented in any detail. There is large uncertainty in particular concerning damages to infrastructure and other uninsured properties, while the modelling of indirect losses is incomplete and disregards important dimensions of social wellbeing. Finally, this analysis focuses on this century alone, however we know that adaptation options, such as dikes, are efficient only up to a certain point that will inevitably be exceeded in the distant future in absence of emission reductions allowing for climate stabilisation. The long-term consequences of climate change are an important argument in favour of mitigation policies and these should not be disregarded.

Acknowledgements The authors want to thank Ian Cochran and Fanny Henriet for their research assistance. Robert Nicholls, Jim Hall, Jonathan Köhler, and two anonymous reviewers have made interesting comments on a previous version of this paper. Finally, Auguste Boissonnade, Rikke Faaborg Edvardsen, Martin Hansen, Niels Bent Johansen, Per Knudsen, Barbara Page, Carlo Sørensen, Per Sørensen, and Steffen Svinth have provided useful information in the course of this project.

\section{References}

Bengtsson L, Hodges KI, Roeckner E (2006) Storm tracks and climate change. J Climate 19:35183543

Bouligand R, Pirazzoli PA (1999) Positive and negative sea surges at Brest. Oceanol Acta 22:153-166

Brookshire DS, Chang SE, Cochrane H, Olson R, Rose A, Steenson J (1997) Direct and indirect economic losses for earthquake damage. Earthq Spectra 13:683-701

Caires S, Swail VR, Wang XL (2006) Projection and analysis of extreme wave climate. J Climate 19:5581-5605

Coles S (2001) An introduction to statistical modelling of extreme values. Springer, p. 208

Fischer-Bruns I, Von Storch H, Gonzalez-Rouco JF, Zorita E (2005) Modelling the variability of midlatitude storm activity on decadal to century time scales. Clim Dyn 25:461-476

Fyfe JC (2003) Extratropical southern hemisphere cyclones: harbingers of climate change? J Climate 16:2802-2805

Geng QZ, Sugi M (2003) Possible change of extratropical cyclone activity due to enhanced greenhouse gases and sulfate aerosols-study with a high-resolution AGCM. J Climate 16:2262-2274

Hallegatte S (2008) An adaptive regional input-output model and its application to the assessment of the economic cost of Katrina. Risk Anal 28(3):779-799. doi:10.1111/j.1539-6924.2008.01046

Hallegatte S, Henriet F, Corfee-Morlot J (2011) The economics of climate change impacts and policy benefits at city scale: a conceptual framework. Clim Change. doi:10.1007/s10584-0109976-5

Hallegatte S, Hourcade J-C, Dumas P (2007) Why economic dynamics matter in assessing climate change damages: illustration on extreme events. Ecol Econ 62:330-340

Hansen JE (2007) Scientific reticence and sea level rise. Environ Res Lett 2:024002 
Hanson S, Nicholls R, Ranger N, Hallegatte S, Corfee-Morlot J, Herweijer C, Chateau J (2011) A global ranking of port cities with high exposure to climate extremes. Clim Change. doi:10.1007/ s10584-010-9977-4

Hoozemans FMJ, Marchand M, Pennkamp HA (1993) A global vulnerability analysis: vulnerability assessment for population, coastal wetlands and rice production on a Global scale, $2 \mathrm{nd}$ edn. Delft Hydraulics, The Netherlands

IPCC (2007) Climate Change 2007: The Physical Science Basis. Contribution of Working Group I to the Fourth Assessment Report of the Intergovernmental Panel on Climate Change. In: Solomon S, Qin D., Manning M, Chen Z, Marquis M, Averyt K B, Tignor M, Miller H L (eds.) Cambridge University Press, Cambridge, p. 996

Kushner PJ, Held IM, Delworth TL (2001) Southern hemisphere atmospheric circulation response to global warming. J Climate 14:2238-2249

Lambert SJ (1995) The effect of enhanced greenhouse warming on winter cyclone frequencies and strengths. J Climate 8:1447-1452

Lambert SJ (2004) Changes in winter cyclone frequencies and strengths in transient enhanced greenhouse warming simulations using two coupled climate models. Atmos-Ocean 42:173-181

Lambert SJ, Fyfe JC (2006) Changes in winter cyclone frequencies and strengths simulated in enhanced greenhouse warming experiments: results from the models participating in the IPCC diagnostic exercise. J Climatol 26:713-728

Leckebusch GC, Ulbrich U (2004) On the relationship between cyclones and extreme windstorm events over Europe under climate change. Global Planet Change 44:181-193

Lindell MK, Prater CS (2003) Assessing community impacts of natural disasters. Nat Hazards Rev 4:176-185

Lowe JA, Gregory JM (2005) The effects of climate change on storm surges around the United Kingdom. Philos Trans R Soc Lond A 363:1313-1328

Lozano I, Devoy RJN, May W, Anderson U (2004) Storminess and vulnerability along the Atlantic coastlines of Europe: analysis of storm records and of a greenhouse gases induced climate scenario. Mar Geol 210:205-225

Meier HEM (2006) Baltic Sea climate in the late twenty-first century: a dynamical downscaling approach using two global models and two emission scenarios. Clim Dyn 27(1):39-68. doi:10.1007/s00382-006-0124-x

Penning-Rowsell EJ, Chatterton T, Wilson E, Potter (2002) Autumn 2000 floods in England and Wales: assessment of national economic and financial losses, Middlesex University, Flood Hazard Research Centre

Pfeffer WT, Harper JT, O’Neel S (2008) Kinematic constraints on glacier contributions to 21stcentury sea level rise. Science 321:1340-1343

Pielke RA Jr, Pielke RA Sr (1997) Hurricanes, their nature and impacts on society. Wiley, New York

Rahmstorf S (2007) Sea-level rise a semi-empirical approach to projecting future. Science 315:368370. doi:10.1126/science. 1135456

Ranger N, Hallegatte S, Bhattacharya S, Bachu M, Priya S, Dhore K, Rafique F, Mathur P, Naville N, Henriet F, Herweijer C, Pohit S, Corfee-Morlot J (2011) An assessment of the potential impact of climate change on flood risk in Mumbai. Clim Change. doi:10.1007/s10584-010-9979-2

Rodriguez E, Morris CS, Belz JE, Chapin EC, Martin JM, Daffer W, Hensley S (2005) An assessment of the SRTM topographic products, Technical Report JPL D-31639, Jet Propulsion Laboratory, Pasadena, California, p. 143

Salathé EP Jr (2006) Influences of a shift in North Pacific storm tracks on western North American precipitation under global warming. Geophys Res Lett 33:L19820. doi:10.1029/2006GL026882

Tierney KJ (1995) Impacts of recent U.S. disasters on businesses: the 1993 midwest floods and the 1994 Northridge Earthquake, Disaster Research Center, University of Delaware

Wang XL, Zwiers FW, Swail VR (2004) North Atlantic Ocean wave climate change scenarios for the twenty-first century. J Climate 17:2368-2383

Woodworth PL, Blackman DL (2002) Changes in extreme high waters at Liverpool since 1768. Int J Climatol 22(6):697-714

Woth K, Weisse R, von Storch H (2006) Climate change and North Sea storm surge extremes: an ensemble study of storm surge extremes expected in a changed climate projected by four different regional climate models. Ocean Dyn 56:3-15. doi:10.1007/s10236-005-0024-3

Yin JH (2005) A consistent poleward shift of the storm tracks in simulations of 21st century climate. Geophys Res Lett 32:L18701. doi:10.1029/2005GL023684 